* Mestrando em Direito pela Universidade Católica de BrasíliaUCB. Especialista em Direito Processual Civil pelo ICPDUNICEUB. Graduado em direito pelo Centro de Ensino Unificado de Brasília - atual UNICEUB. Graduado em Licenciatura História pelo Centro de Ensino Unificado de Brasília - atual UNICEUB. Professor de Processo Civil no UNIPLAN

E-mail: marcotoliveira2009@ hotmail.com

** Doutor em Economia pela Universidade de Brasília UnB. Mestre em economia pela Universidade Federal Fluminense. Graduação em Economia pela Universidade Federal de Uberlândia. Professor da Escola de Políticas Públicas e Governo da Fundação Getúlio Vargas-FGV. E-mail: benjaminm.tabak@gmail. com

\section{A Contribuição da Análise de Custo-Benefício na Avaliação da Eficiência de Regras Fundiárias do Distrito Federal}

\author{
The Contribution of Cost-Benefit Analysis in The \\ Evaluation of The EfFiciency of Public Land Rules of \\ DisTRITO FEDERAL
}

\section{Marco Tulio Chaves Oliveira* Benjamin Miranda Tabak**}

Como citar: OLIVEIRA, Marco Tulio Chaves; TABAK, Benjamin Miranda. A contribuição da análise de custo-benefício na avaliação da eficiência de regras fundiárias do distrito federal. Revista do Direito Público, Londrina, v. 13, n. 3, p. 72-90, dez. 2018. DOI: $10.5433 / 24157-108104-1.2018 v 13 n 3$ p 72. ISSN: 1980-511X.

Resumo: Este artigo se propõe a avaliar a eficiência de algumas regras do Plano Diretor do Ordenamento Territorial (PDOT) do Distrito Federal, sob a ótica da Análise Econômica do Direito (AED). Aborda implicações práticas de tais normas no comportamento dos habitantes daquela unidade federativa, no contexto da política pública de terras. Expõe os princípios básicos e definições daquele ramo do conhecimento jurídico, em particular o critério de Kaldor-Hicks e a análise de custobenefício. Conclui que a imposição sancionatória prevista por aquele regramento não interfere de maneira eficaz junto aos tomadores de decisão das negociações fundiárias. A lei também deve prever incentivos ex ante tanto para os agentes integrantes das trocas econômicas atuais quanto para eventuais danos causados por negligências vindouras. Ao final, faz sugestões quanto a futuras propostas legislativas relacionadas ao tema.

Palavras-chave: Plano diretor do ordenamento territorial; Análise Económica do direito. Eficiência; Política pública de terra.

Abstract: This paper evaluates the efficiency of some of the articles of the "Plano Diretor do Ordenamento Territorial" 
(PDOT) of the Federal District, utilizing Law and Economics in order to understand them. Moreover, this study addresses the practical implications of such norms on the behavior of a city's population, specifically in the context of public land policy. Furthermore, this research examines primordial legal concepts within this theme - particularly the Kaldor-Hicks criterion and the cost-benefit analysis. This paper concludes that the penalty imposed by this law does not influence the natural consequences of land negotiations. Additionally, this study also advocates for more incentives as a means to better these current economic exchanges and avoid possible damages caused by negligence. Ultimately, this study suggests some future legislative proposals in order to solve some of the studied legislative inconsistencies.

Keywords: Plano Diretor do Ordenamento Territorial (PDOT); Law and Economics; Efficiency; Public Land Policy. 


\section{INTRODUÇÃO}

O texto constitucional determinou a elaboração de um plano diretor ${ }^{1}$ para centros com população superior a vinte mil habitantes, cujo principal objetivo é servir como instrumento da política de desenvolvimento e expansão, devendo ser aprovado pela Câmara Municipal, sinalizando que a lei ordinária deverá estabelecer, do ponto de vista local, a disciplina para o uso do solo, e sobre o qual autores contemporâneos indicam novos pontos de vista, equacionando elementos como gestão democrática, participação local e sustentabilidade (TYBUSCH; GREGORI, 2011; LACERDA, 2014), o que foi concretizado no Distrito Federal a partir do ano de 2009 por intermédio da Lei Complementar n. 803, de 25 de abril de 2009, denominado Plano Diretor do Ordenamento Territorial $^{2}$ (PDOT).

Nesse contexto, o presente artigo tem por objetivo responder a seguinte questão: em que medida a análise do custo-benefício contribui para avaliar a eficiência de regras fundiárias relativas a (e na solução dos conflitos pela) propriedade/posse da terra urbana no Distrito Federal? Uma das razões para formular tal pergunta pode ser buscada na quantidade de ações judiciais ${ }^{3}$ que envolvem a disputa pela propriedade (ou posse) da terra, entre particulares e o Governo Distrital, cujas taxas de aumento e diminuição são variáveis.

O custo-benefício, exposto na sequência deste trabalho, é um dos muitos conceitos presentes numa área (jurídica) recente, denominada Análise Econômica do Direito ${ }^{4}$ (AED), que utiliza princípios da Economia na avaliação de problemas de ordem prática (a exemplo dos conflitos fundiários), indicando possíveis soluções para tais conflitos. Partindo de premissas diferentes das observadas tradicionalmente no mundo jurídico, utiliza argumentos e perspectivas diversas (COOTER, 2010; PORTO, 2011; RODRIGUES, 2007; TABAK, 2015), preocupada, por exemplo, com o impacto que a regra de direito, estabelecida pelo legislador para resolver disputas específicas, poderá ter no comportamento de partes que estiverem em condições semelhantes no futuro.

O texto divide-se em duas partes. Na primeira, dispositivos iniciais do PDOT serão objeto de análise pelo diálogo produzido por autores da AED, expondo elementos geralmente não considerados no direito. $\mathrm{Na}$ segunda, relacionados alguns princípios fundamentais e conceitos utilizados pela AED, valer-se-á do critério de Kaldor-Hicks para a apreciação da eficiência daqueles dispositivos, mediante a avaliação do custo-benefício de situações específicas do PDOT, podendo tal padrão ser considerado como meio de exame do bom desempenho da lei (TABAK, 2015) para, ao final, indicar algumas sugestões a serem adotadas nas futuras propostas legislativas

\footnotetext{
1 Constante do art. 182 e $\S 1^{\circ}$, nos seguintes termos: A política de desenvolvimento urbano, executada pelo Poder Público municipal, conforme diretrizes gerais fixadas em lei, tem por objetivo ordenar o pleno desenvolvimento das funções sociais da cidade e garantir o bem-estar de seus habitantes. $\S 1^{\circ} \mathrm{O}$ plano diretor, aprovado pela Câmara Municipal, obrigatório para cidades com mais de vinte mil habitantes, é o instrumento básico da política de desenvolvimento e de expansão urbana.

2 Por sua vez, atende as diretrizes previstas na Lei Federal n. 10.257, de 10 de julho de 2001 (Estatuto das Cidades).

3 Dados obtidos no site oficial do Tribunal de Justiça do Distrito Federal e Territórios (TJDFT), sobre os quais se falará adiante.

4 Mencionam-se os nomes de Ronald H. Coase (The problem of social cost) e Guido Calabrese (Some thoughts on risk distribution and the law of torts), no início da década de 1960, como seus precursores.
} 
da normatização fundiária.

\section{PLANO DIRETOR DO ORDENAMENTO TERRITORIAL (PDOT) DO DF: UMA ANÁLISE INICIAL}

A finalidade do $\mathrm{PDOT}^{5}$, exposta no art. $2^{\circ}$, sugere que o comportamento que se pretende obter, por parte dos habitantes do Distrito Federal (DF), reverterá em benefícios que atingirão o maior número possível de pessoas. Pode-se fazer tal afirmação num contexto que relaciona a função social da propriedade ${ }^{6} \mathrm{com}$ as definições de interesse social e conveniência. Tal relevância coletiva (interesse social) trata do melhor bem-estar, para o maior número possível de indivíduos. Por sua vez, conveniência diz respeito a tudo aquilo que busca otimizar recursos ou alcance de recursos de tempo, energia e capital que evitem o desperdício (CACHO, 2012). O bem-estar social seria avaliado pela soma simples e não ponderada da utilidade individual (PORTO, 2014).

Uma decorrência da utilização da propriedade privada fundiária, considerando o dispositivo indicado e partindo de algumas premissas utilizadas pela análise econômica do direito, seria que aquele direito atribui a alguém que mora no Distrito Federal a faculdade de decidir a utilização de seu patrimônio, significando a possiblidade de transação do direito de domínio numa economia de mercado, assegurando que sua titularidade poderá ser transferida de quem lhe confere menos para quem the atribui mais valor (RODRIGUES, 2007). Considerando o modo genérico como aquele direito foi inserido no contexto do PDOT, a utilização da propriedade fundiária atenderia um interesse geral (ou função social), toda vez que duas (ou mais) pessoas pudessem estabelecer, por exemplo, uma negociação de compra e venda de um imóvel entre particulares.

Como se verá adiante, o fato do plano diretor territorial do Distrito Federal estar em sintonia formal com o texto constitucional não impede a ocorrência de ilícitos fundiários, o que poderia em parte explicar o surgimento e crescimento de condomínios irregulares (PRADO JUNIOR, 1998). Por outro lado, a destinação geral indicada, quanto ao uso do solo urbano no DF remete a alguns requisitos exigidos dos proprietários da terra, os quais devem ser satisfeitos para que se considere adequada a utilização fundiária, previstos no art. $40, \S \S 1^{\circ}$ e $2^{\circ}$, do $\mathrm{PDOT}^{7}$. Obedecidas tais obrigações, cumprida estaria a finalidade da regra de comportamento. Talvez não fosse essa a conclusão, caso se fizesse uma avaliação do custo-benefício de tais normas, objeto da próxima seção. Isso porque o simples fato de haver regramento formal que se proponha a reprimir ocupações ilegais não é o suficiente para impedir tal ocorrência.

\footnotetext{
5 Nos seguintes termos: "propiciar o pleno desenvolvimento das funções sociais da propriedade urbana e rural e o uso socialmente justo e ecologicamente equilibrado de seu território, de forma a assegurar o bem-estar de seus habitantes". O legislador não informou exatamente o significado da expressão "bem-estar".

6 Prevista expressamente em dispositivos da Constituição Federal de 1988, dentre os quais: art. 50, inc. XXIII ("XXIII - a propriedade atenderá a sua função social"), art. 170, inc. III e art. 182, §2 ("a propriedade urbana cumpre sua função social quando atende às exigências fundamentais de ordenação da cidade expressas no plano diretor").

7 Que assim dispõe: Art. 40. O coeficiente de aproveitamento é a relação entre a área edificável e a área do terreno, conforme segue: I - coeficiente de aproveitamento básico; II - coeficiente de aproveitamento máximo. $\S 1^{\circ} \mathrm{O}$ coeficiente de aproveitamento básico corresponde ao potencial construtivo definido para o lote, outorgado gratuitamente, a ser aplicado conforme indicado nos Anexos V e VI desta Lei Complementar. $\$ 2^{\circ} \mathrm{O}$ coeficiente de aproveitamento máximo representa o limite máximo edificável dos lotes ou projeções, podendo a diferença entre os coeficientes máximo e básico ser outorgada onerosamente, e será aplicado conforme indicado nos Anexos V e VI desta Lei Complementar.
} 
É possível indagar, ainda, se na elaboração da lei fundiária distrital o autor do projeto de lei fez algum tipo de projeção ou pesquisa relativa à toda cadeia que envolve a construção civil, ao indicar o "coeficiente de aproveitamento básico" (art. 40, inc. I, $\S 1^{\circ}$, PDOT). Considerado apenas como normatividade, parece que ao PDOT não foram incorporados aspectos de natureza prática, como a possibilidade de que alguém deliberadamente ignore a regra que determina o registro imobiliário prévio como pressuposto para a venda legítima de uma casa por uma pessoa a outra ${ }^{8}$.

Outra hipótese, sobre a qual se falará adiante, é a de que o legislador não considerou que alguém pode avaliar que a multa administrativa, prevista em lei, para o caso de serem violadas as regras fundiárias distritais, não representa impeditivo para a realização da venda de um imóvel num condomínio irregular, pelo simples fato de que o percentual daquela sanção é baixo o suficiente a ponto do comprador avaliar como suportável o risco dessa despesa. Tais exemplos demonstram que indivíduos que participam de transações (de mercado) também levam em consideração elementos extra-jurídicos, para tomarem suas decisões. Ocorre que estas, por sua vez, podem gerar consequências socialmente indesejadas, o que se observa no modelo de formação do espaço urbano do Distrito Federal. O quadrilátero brasiliense deve ser considerado como um aglomerado urbano formado por um núcleo (Brasília), cuja sede é o Plano Piloto, diversos centros secundários (cidades-satélites) e uma extensa periferia, conhecida como entorno, ou seja, diversos municípios do Estado de Goiás, tais como Luziânia, Planaltina, Águas Lindas, interdependentes entre si (STEIBERG; MANIÇOBA, 2009).

Isso significa que (inclusive diariamente) há um fluxo migratório entre tais regiões. Tais movimentos também são realizados com a intenção de fixar residência no DF, o qual, ao menos de modo expresso, não foi mencionado no art. 37 do PDOT, sugerindo que o impacto causado por tal não foi considerado na elaboração da política fundiária. Variadas clientelas com diferentes (e às vezes antagônicos) interesses, oriundas das regiões mencionadas, deslocam-se para o Distrito Federal na busca da melhores condições e, ao participarem de negociações que envolvam bens imóveis, não dispõem do direito de fazer o parcelamento do solo sem antes promover a regularização, aprovada previamente por órgãos previstos em lei ${ }^{9}$, o que pode contribuir, repita-se, para a formação de loteamentos irregulares, gerando demandas, expectativas e eventuais conflitos (SILVA, 2006).

Uma comparação a ser feita na situação descrita, que diz respeito à concepção da propriedade e, por extensão, sua função social, é a de que, de modo diverso ao que faz a dogmática jurídica, a AED não busca necessariamente explicar o conceito de tal direito, mas antever as consequências de formas alternativas de normas a ele relacionadas (PORTO, 2017).

\section{A ANÁLISE ECONÔMICA DO DIREITO (AED) E A EFICIÊNCIA NORMATIVA}

Analisados os dispositivos indicados na seção anterior, nesta será feita uma breve

8 Veja Dayrell e Tabak (2017) para uma discussão à luz da AED sobre o sistema de informações territoriais.

9 A regularização fundiária no Distrito Federal é realizada por intermédio de uma Empresa Pública, a TERRACAP (Companhia Imobiliária de Brasília), instituída pela Lei Federal n. 5.861, de 12 de dezembro de 1972. 
contextualização da AED, apresentando alguns elementos utilizados na apreciação de institutos jurídicos, dentre eles o critério de Kaldor-Hicks, com a finalidade de avaliar a eficiência de algumas regras da política pública fundiária do Distrito Federal.

\subsection{Princípios e conceitos}

Tradicionalmente, a Economia tinha por objeto de estudo os aspectos relativos à produção, ao comércio, à distribuição da riqueza e fatos correlatos. Porém, na metade do século XX, desenvolveu um modo próprio de estudar e avaliar os fenômenos sociais acerca das escolhas sobre a utilização dos recursos (RODRIGUES, 2007). Outra perspectiva é a de que aquela ciência fornece elementos gerais de análise, tais como uma teoria comportamental no sentido de prever como as pessoas reagem às leis bem como a previsão dos efeitos das políticas sobre as distribuições da renda e da riqueza (COOTER, 2010). Para relacionar o campo econômico e o jurídico é que se faz necessária uma metodologia que considere as preferências e escolhas individuais, tomando o direito de propriedade, no sentido privado de seu uso, mencionado na primeira parte, ampliadas (e transformadas) em decisões sociais (SZTAJN, 2005).

Fundamentalmente, o método econômico utiliza três princípios para elaboração de seu raciocínio. Primeiro, parte da premissa que os agentes atuam de forma racional ${ }^{10}$ para fazerem suas escolhas a fim de minimizar o seu custo, o que poderá interferir na obtenção de um resultado que maximize seu bem-estar. Em segundo lugar, no processo de avaliação das alternativas ocorre um equilíbrio, aplicável diretamente à livre negociação dos agentes econômicos, em situação de mercado, sendo esta a forma como, em determinadas circunstâncias, a interação social determina as opções disponíveis. Por fim, o critério básico para avaliar a ação humana é a eficiência, que será atingida levando-se em consideração alguns critérios (RODRIGUES, 2007), sobre os quais se falará adiante. É possível, porém, que o tomador de decisão possa não ser completamente racional e ficar sujeito a algum viés de julgamento, ou seja, algum tipo de interferência durante suas escolhas. Tome-se como exemplo uma pessoa que deseje adquirir um terreno para nele construir uma casa e abrigar sua família.

Em que pese, do ponto de vista ideal, tratar-se de uma proposta plausível, se avaliar que não possui dinheiro suficiente para negociar diretamente com quem seja proprietário de um imóvel, mas, ao invés disso, com alguém que esteja em situação irregular, poderá futuramente gerar uma situação na qual será demandado judicialmente. Dentre outros motivos, isso ocorreria porque geralmente os agentes tomadores de decisão consideram os benefícios e os custos particulares e não os sociais (TABAK, 2015) de seu comportamento.

Além dos princípios indicados, a AED tenta explicar e prever o comportamento dos agentes e pessoas atingidas pela lei e, por outro lado, busca aperfeiçoar a regra de direito indicando relações,

10 Significando agir racionalmente: 1) ter preferências pré-determinadas; 2) que as consequências das escolhas acarretem uma utilidade; 3 ) a opção feita por uma das alternativas é feita se o benefício decorrente supera o custo para obtenção do bem pretendido (RODRIGUES, 2007). Racionalidade também implica (POSNER, 1998) em decisões, tomadas geralmente em condições de incerteza. 
sejam sobre eficiência econômica, distribuição da riqueza ou outros valores, nas quais possam haver consequências indesejadas pelo legislador (POSNER, 1998). Nesse contexto, podem ser feitas duas perguntas (PORTO, 2014): como o comportamento dos indivíduos é afetado pela lei? E outra, não menos importante: quais são as melhores normas em termos de medidas de bem-estar social e como comparar diferentes regras? Se formulada de uma outra forma, qual o impacto ou resultado que a norma jurídica, sob certas condições, pode produzir em determinada comunidade?

Outros questionamentos podem ser feitos (COOTER; ULEN, 2010): como uma regra estabelecida pelo legislador para resolver disputas específicas no âmbito de trocas atuais irá afetar o comportamento de partes que se encontrem em situação semelhante no futuro? E essa reação é desejável? Para responder tais perguntas a investigação inicia a partir de um conceito básico, a saber, eficiência, central no enfoque normativo da análise econômica (CACHO, 2012) e fator relevante a ser considerado na elaboração de políticas públicas que se proponham a atingir determinada meta a um custo menor.

Outra definição que tem lugar na análise econômica do direito é o de externalidade, que pode ser intuído mediante um exemplo. Na tragédia ocorrida no ano de 2015, próximo à cidade mineira de Mariana, ocorreu um dos maiores desastres ambientais no Brasil. Houve rompimento de uma barragem de contenção de resíduos e uma incontável quantidade de lama e detritos causou enormes danos, com perda de vidas humanas, com prejuízos ambientais e para populações locais e distantes. Todas as pessoas que não participavam da extração de minérios foram atingidas e viram seu patrimônio danificado, às vezes de modo irreparável, numa ocorrência a que não deram causa. Neste exemplo, consideram-se externalidades os benefícios ou custos que as atividades da mineradora impuseram a terceiros, que não são expressas pelo sistema de preços.

\subsection{Análise econômica do direito: eficiência e critérios}

$\mathrm{Na}$ análise econômica, o termo eficiência possui alguns significados. Tradicionalmente, refere-se à otimização de alguma medida de valor (PORTO, 2014). Com isto se quer dizer que ao ser atribuída importância a determinado bem, uma regra ou juízo será considerado eficiente se conseguir maximizar a utilidade de tal objeto. Acrescentem-se duas definições: bem-estar individual e utilidade. O primeiro pode ser medido pela utilidade que o agente retira das decisões que toma, assim como as que não tomou mas tinha condições em fazê-lo. A segunda abrange desde os bens imateriais, a exemplo do amor, da alegria e da desilusão (PORTO, 2014) até aqueles com valor economicamente aferível, tais como um carro ou um terreno.

Mas há coisas que as pessoas se importam do ponto de vista individual, mas que não são aspectos da essência humana (ADLER; POSNER, 2009), a exemplo de evitar a dor, socializar-se e fazer sexo. Neste sentido, não necessariamente entrariam numa típica análise de custo-benefício. Em termos mais restritos, a Economia se empenhou em delinear critérios que pudessem ser utilizados na avaliação da eficiência quanto à circulação da riqueza, ou seja, de quem menos atribui 
para quem mais confere valor. O primeiro deles, denominado ótimo de Pareto ${ }^{11}$, pode ser proposto da seguinte forma: quando alguém fica melhor, numa sociedade, considerando suas circunstâncias anteriores e mediante a mudança de atribuição de bens, sem que ninguém fique pior, tal situação é considerada eficiente (SZTAJN, 2005). A fórmula acima tem lugar num cenário de competição perfeita ou ideal, em que os agentes possuem as mesmas condições para realizarem escolhas e de atuação econômica, significando que não será adequada qualquer reorganização dos fatores produtivos ou formas de produtividade que possibilitem o aumento da utilidade de uma pessoa sem reduzir de alguma outra.

Outro padrão, tradicionalmente utilizado, é denominado eficiência de Kaldor-Hicks ${ }^{12}$, pelo qual se determinada decisão (ou regra), tendo como parâmetro um somatório individual simples, gerar utilidade para os integrantes de uma sociedade, será considerada eficiente (PORTO, 2014). Aqui, a preocupação ou finalidade é a proposição, do ponto de vista coletivo, de uma política que gere benefícios para todas as pessoas de uma cidade. Retomando a comparação dos critérios de eficiência de Pareto e Kaldor-Hicks, se aplicados na avaliação de eficiência de uma norma jurídica, é possível constatar a diferença de resultados. Assim, normas relativas ao uso da propriedade urbana que pretendessem assegurar o "bem-estar de seus habitantes", ou seja, em que se desencadeassem utilidades coletivas e não meramente individuais, estariam cumprindo bem o seu papel. Se analisadas sob o critério de Pareto, as regras fundiárias a serem vistas adiante deveriam, por um lado, fazer com que os agentes econômicos, nas relações que envolvessem o gozo das prerrogativas dos direitos de propriedade dos bens imóveis no Distrito Federal (DF), obtivessem vantagens e, por outro, não houvesse uma única pessoa com piora do seu bem-estar. $\mathrm{Na}$ prática, isso significaria a inexistência de déficit habitacional pelo fato de todas as pessoas poderem adquirir imóveis e também que nenhuma deixe de compra-los em razão do alto preço de mercado ou mesmo por outras razões.

\subsection{O argumento de Coase e análise de custo-benefício}

Com o aprofundamento dos estudos sobre a conveniência em se estabelecer de modo adequado os direitos de propriedade ${ }^{13}$, o economista britânico Ronald Coase desenvolveu um argumento, também conhecido como Teorema de Coase, no qual propôs que o Estado pode intervir para obrigar os agentes a internalizar as externalidades, não significando, ressalta, que tal interferência seja necessária. Alegava que a intervenção estatal para impor uma alteração no comportamento individual de uma das partes envolvidas numa transação só será eficiente se ela puder eliminar, ao menor custo, o inconveniente da externalidade (RODRIGUES, 2007). Esta, em si mesma, não seria impedimento para a eficiência do mercado, podendo funcionar mesmo na presença de externalidades e desconsiderados os custos de transação, os quais podem pôr em risco a eficiência das transações. Se houver cooperação entre os agentes econômicos envolvidos nas

11Em homenagem ao economista italiano Vilfredo Pareto (1848-1923).

12 Refere-se aos economistas Nicholas Kaldor (1908-1986) e John Hicks (1904-1989).

13 “The Problem of social cost”, publicado no início da década de 1960. 
trocas, afirma, a regra de direito não é importante ou fundamental, do ponto de vista prático, visto que em tal situação, o uso dos recursos é eficiente.

De modo expresso, o teorema pode ser enunciado da seguinte forma: se todos os obstáculos à negociação, ou seja, os custos de transação, forem iguais a zero, a eficiência do uso dos recursos disponíveis é resultado da negociação privada, sendo irrelevante a designação dos direitos de propriedade atribuíveis ao evento (COOTER; ULEN, 2010). Considerando a possibilidade de haver conflitos nas transações entre os agentes e, caso tais disputas sejam levadas ao Poder Judiciário, é possível afirmar que as decisões proferidas nos processos cumprem a tarefa de atribuir valor a certos bens. Ocorre que a prática judicial, em si mesma e do ponto de vista social, gera um custo (GONZÁLEZ, 2001), e a pergunta a ser feita é: não haveria um caminho menos oneroso para se atingir o mesmo resultado?

A questão indicada pode ser encarada também como um esquema de definição do valor e das escolhas das partes envolvidas nas negociações. Ocorre que da forma como foi proposto o argumento de Coase, ou seja, presumindo que as trocas voluntárias realizadas pelos agentes encarregados do seu próprio bem-estar não dependem da distribuição dos direitos de propriedade, tal situação acontece num mundo ideal e, por isso, estar-se-ia diante de um Coase ideal (GONZÁLEZ, 2001). Porém, em um Coase real, existem custos de transação (ou de mercado), os quais são computados nas negociações (contratos) e, nesta situação, a distribuição dos direitos de propriedade tem importante função.

Assim, o agente racional fará a ponderação entre o benefício a ser obtido e o valor que deverá pagar, caso não cumpra a sua obrigação contratualmente estabelecida. Supondo que a utilidade seja superior ao custo a ser pago, executará a sua parte do acordo, o que não implica em eficiência, pois esta diz respeito não apenas ao cálculo econômico privado em jogo, mas também às consequências que a efetivação do contrato possa gerar para o conjunto da sociedade (RODRIGUES, 2007). Outro aspecto a considerar, retomando a voluntariedade das trocas, é a consequência trazida pela elevação dos custos da transação. Se forem excessivos, a ponto de impedir a negociação, a melhor alternativa é a indenização para uma das partes, por intermédio de uma ação ${ }^{14}$ (COOTER; ULEN, 2010).

Inversamente, se os custos de transação forem baixos, contribuindo para a operação, a ação mandamental é mais eficiente do que a indenizatória ${ }^{15}$. Na prática, isto significaria, por exemplo, que se uma lei nova autorizasse o aumento do percentual da taxa de juros nos contratos de financiamento para a aquisição de imóveis, por se tratar de uma externalidade, ou seja, um custo imposto pelo Estado nos intercâmbios privados, poderia resultar em inexecução parcial ou total

14 Os autores informam (p. 105) que os custos de transação são aqueles presentes nas trocas ou comércio. Já o termo "ação", insere-se no contexto do common law (p. 112). Neste ambiente jurídico, além da indenização pecuniária, o outro remédio disponível em um tribunal é da equidade ("equity"), ou ação mandamental. Tal sistema, presente em países como a Inglaterra e os Estados Unidos, ainda utiliza a distinção entre common law (direito comum - numa tradução livre) e equity, comparável ao direito público e privado, observado na tradição romano-germânica (DAVID, 1978).

15 No caso brasileiro, o art. 927 do Código Civil prevê uma regra geral, conferindo o direito de reparação civil a quem sofreu algum tipo de dano, o que pode ser aplicado, por exemplo, ao contrato de compra e venda ou prestação de serviços. 
do acordo, visto que uma das partes não esperava tal intensificação. A relação entre o teorema de Coase e os custos de transação é que estes determinam a regra legal a ser adotada. Se tendem a zero, o uso eficiente dos recursos não dependerá da distribuição do direito de propriedade. Se não forem nulos, a atribuição deste direito será fundamental.

Além dos conceitos vistos, a AED também utiliza outro instrumental, denominado análise de custo-benefício. Por meio dela, se verifica se os agentes comparam os benefícios e os custos de diferentes alternativas, sejam econômicas, sociais ou culturais. É feita num contexto de escolhas, traduzidas num nível de bem-estar dos agentes (PORTO, 2014). Dentre as opções numa dada situação, o indivíduo escolherá aquela que, assim entende, lhe ofereça o maior percentual de utilidade ou satisfação, descartando outras que não atendam esse critério ou possam acarretar maior custo em sua obtenção.

Afirma-se que a avaliação de custo pode ser usada como um padrão para estimar quais políticas maximizam o bem-estar geral de determinada população. Desta forma, a grande vantagem daquela análise é oferecer uma estrutura quantitativa e sistemática para elaboração dos trade-offs, que tem um sentido econômico de conflito de escolha. Fica caracterizado quando o agente, visando a resolução de um problema gera outro como consequência, conduzindo a determinada decisão, sobre qual ou quais são as melhores opções numa dada situação (ADLER; POSNER, 2009).

\subsection{Análise de eficiência do regramento fundiário distrital}

Um dos custos da política pública fundiária urbana previstos no PDOT, que prevê a imposição de sanções para o agente que viola as normas do plano diretor, é a possibilidade de que tais penalidades, considerado o retrospecto e o contexto administrativo no Distrito Federal (DF), sejam encaradas pela população como ineficientes, gerado pela desconfiança dos habitantes em relação ao governo distrital quanto à atividade fiscalizatória e de repressão de comportamentos ilícitos, a exemplo da formação (e continuidade) dos condomínios irregulares existentes na Capital Federal.

Expressamente o PDOT, impõe multa para quem violar suas regras bem como o percentual da penalidade a ser aplicado a quem descumprir tais normas ${ }^{16}$. Porém, ao longo de um considerável período, o governo distrital não conseguiu demonstrar efetivo cumprimento da ordem da cidade no sentido de coibir, de maneira eficaz, a ocupação irregular do solo urbano. Uma das frentes de atuação fiscalizatória que apresenta deficiência diz respeito à uma situação fática de ocupação, associada à falta de uma consistente política habitacional, na qual o governo local encarou como melhor alternativa as sucessivas regularizações de áreas irregulares (TABAK; FERREIRA FILHO,

16 Respectivamente, nos arts. 250 , incs. I a V, e $259, \S \S 1^{\circ}$ e $3^{\circ}$, nos seguintes termos: Art. 250 . Toda ação ou omissão que viole as normas previstas neste Plano Diretor, praticadas por pessoas físicas ou jurídicas, serão punidas com a aplicação das seguintes penalidades administrativas, sem prejuízo das sanções penais previstas na legislação federal: I - multas; II - embargo; III - interdição; IV - suspensão parcial ou total de atividades; V - demolição. Art. 259. Constituem infrações administrativas, independentemente da aplicação de sanções penais ou cíveis: [...]; $\S 1^{\circ}$ Fica 0 infrator sujeito a multa de 3\% (três por cento) a 10\% (dez por cento) do valor do imóvel, considerado com base na planta de valores imobiliários utilizada para cálculo do IPTU; (...); §3 $3^{\circ}$ Em caso de reincidência, será cominada ao infrator multa de $10 \%$ (dez por cento) a 15\% (quinze por cento) do valor do imóvel. 
2016), no que se refere a invasão de áreas de proteção ambiental permanente.

Em tal situação e considerando apenas os argumentos utilizados para a elaboração do critério de Kaldor-Hicks, é possível que não sejam suficientes para uma análise no caso do regramento fundiário no Distrito Federal. O que se indica é que a perspectiva de aumento da riqueza, na forma ali proposta, deve ser revista, pois somente a voluntariedade das transações já não é suficiente para demonstrar a eficiência em situações nas quais o princípio da maximização (da riqueza) entra em choque com a voluntariedade dos agentes envolvidos na transação (VALDÉS PRIETO, 2006). Considerando uma negociação relativa a um imóvel quais custos seriam considerados para que façam ou deixem de fazer tal transação? Numa outra forma: o fato de haver a possibilidade legal de ser aplicada uma multa administrativa com percentual variando entre três e dez por cento seria impeditivo para que deixassem de negociar? Se respondida levando em conta a maximização da riqueza que abranja a maior quantidade possível de pessoas, na qual os bens são transferidos de quem menos para quem mais lhe confere valor, a resposta seria negativa. Ou seja, a transação não deixaria de ser feita por haver a possiblidade da imposição sancionatória.

Isso quer dizer que uma proposta legislativa também deveria considerar tais decisões, ao invés apenas prever de modo genérico a imposição de uma penalidade administrativa. $\mathrm{Na}$ elaboração da política pública seria possível incorporar os principais objetivos da análise de custobenefício, ou seja, atingir a eficiência por meio da análise de todos os custos e benefícios, além de alcançar uma maior igualdade, conferindo pesos diferentes a grupos atingidos por iguais medidas (TABAK, 2015). O percentual adotado pelo legislador, a título de sanção pelo descumprimento das regras previstas no PDOT, numa transação relativa a um imóvel em situação irregular pode simplesmente não ser considerada como obstáculo pelas partes envolvidas num contrato.

Parece haver um consenso acadêmico de que a ocupação irregular de terras é um dos fatores demonstrativos de uma tensão fundiária no Distrito Federal (GUIMARÃES, 2013; PRADO JUNIOR, 1998; STEIBERG; 1999; SILVA, 2006), repercutindo em vários segmentos (especulação imobiliária, meio ambiente, mobilidade urbana). Um dos indicadores de conflito é a quantidade de ações judiciais de reintegração e manutenção de posse propostas perante o Poder Judiciário (Tribunal de Justiça do Distrito Federal e Territórios - TJDFT), constante do quadro abaixo, sinalizando que a disputa pela posse ou propriedade de imóveis, ao menos no que se refere ao domínio público, apresenta patamar consideravelmente alto.

Tomou-se por amostragem o período imediatamente anterior à publicação do PDOT, entre os anos de 2007 e 2009, em que ocorreu um aumento dos casos distribuídos a uma taxa de 50,21\% (período 2007-2008) e uma diminuição de 26,16\% (período 2008-2009). Tais números sugerem por um lado e em termos absolutos, que a entrada em vigor da nova legislação contribuiu diretamente para a redução das disputas judiciais envolvendo a regularização fundiária urbana e, por outro, que em se tratando da administração pública da demanda por terras na Capital da República, a atuação do Estado se mostraria relativamente bem-sucedida. 
Quadro 1 - Quantidade de ações

\begin{tabular}{|c|c|}
\hline Ano & Quantidade de açoes propostas $^{1}$ \\
\hline 2007 & $\mathbf{2 9 8 0}$ \\
\hline 2008 & $\mathbf{5 9 8 5}$ \\
\hline 2009 & $\mathbf{8 1 0 7}$ \\
\hline \multicolumn{2}{|c}{ Fonte: próprio autor } \\
\hline
\end{tabular}

Defende-se aqui, também, que o quantitativo (maior ou menor) das demandas judiciais não necessariamente deve ser associado à eficiência normativa, ao menos do regramento fundiário. Foi mencionado outro fator que diretamente contribui para a manutenção das demandas por terrenos urbanos no DF, a saber, a regularização de loteamentos em (vários casos, total) desacordo com a disposição normativa, o que pode ser causa de incentivo para agentes que participem ou promovam invasões. Isso porque haveria, historicamente, uma relação entre a variação do perfil político dos sucessivos governos (ou seja, da orientação ideológico-partidária) distritais e a regularização de regiões habitadas e consolidadas no tempo, em desacordo com o regramento jurídico, mas que já constituíam parcela significativa da população (SENA, 1970).

Em casos assim, a análise de custo-benefício se mostraria como uma maneira de garantir o estabelecimento de prioridades e prever futuros obstáculos à uma regulamentação desejável, seja qual for o critério de decisão para a escolha das prioridades de uma comunidade (SUSTEIN, 1999). O sistema concebido pela AED pressupõe a existência de uma ordem jurídica que tutele as pessoas, as quais realizam transações no dia a dia em seus próprios ambientes, que podem apresentar variadas dificuldades de finalização ou até mesmo inviabilizar tais negócios. Caso isso ocorra, a solução dos problemas das transações voluntárias é reenviada para o conjunto jurídico de regras, sejam justas ou injustas (VALDÉS PRIETO, 2006).

Nesse contexto, o simples fato de haver a previsão legal, no PDOT, de impor multa administrativa (ao menos nos patamares ali previstos), concomitante à uma prática histórica de regularizar comportamentos contrários à lei, pode contribuir para ineficiência da política pública. Deve haver, além disso, credibilidade suficiente para que a comunidade acredite na eficácia do poder público, entendida como a descoberta da atividade contrária à norma e consequente punição (TABAK, 2016). Apesar de haver um extenso conjunto de regras para o ordenamento da terra urbana no Distrito Federal, isso não parece impedir a prática de agentes privados em participar de transações que envolvam imóveis em desconformidade com aquela normatização.

As já elencadas sanções do art. 250, incs. I a V do PDOT, igualmente podem suscitar dúvidas quanto à sua eficiência. Isso porque dizem respeito a uma situação observada pelo direito, a saber, a norma ex ante e ex post facto. De maneira simples, uma lei ex post facto pode ser definida como aquela editada após a ocorrência do fato ou após a prática de um ato, a qual muda as consequências legais ou relações de tal evento ou ação. Esta definição está inserida no contexto da common law estadunidense, no qual há uma proibição geral de elaborar (no nível federal e estadual) qualquer lei ex post. Tal indicação foi explicitamente formulada pela Suprema Corte norte-americana, visto que uma regra ex post compreende alguns pressupostos ou características (ROBINSON, 2005) sendo 
assim considerada, por exemplo, toda norma que criminalizar um comportamento praticado antes de sua vigência e que, à época de sua prática (da ação), ou seja, antes da regulamentação, não era ilícita e, além disso, a lei nova pune o agente.

É possível questionar se a realização de um ato que no passado era tido como danoso pode, por intermédio de uma nova legislação, tornar-se lícito. Nesta situação, deve ser considerado responsável quem praticou a ação, sob a lei atual, se o comportamento ex ante incorreto mas admitido ex post facto (for considerado como) correto pela nova regra causou prejuízo a alguém? Para essa pergunta nunca foi dada uma resposta clara (PORAT, 2014). Veja-se que o formulador da política fundiária do Distrito Federal, ao que parece, estabeleceu um gradiente punitivo administrativo, variando desde o embargo até a demolição da construção, sugerindo que o comportamento ex post, ou seja, o levantamento da edificação é considerado ilícito e deve ser sancionado. Porém, ao menos explicitamente, não menciona que as transações antes da obra, ou seja, o contrato de compra e venda do imóvel em si mesmo é ilícito.

Vale lembrar que a análise de custo-benefício anteriormente indicada denota o uso do conceito de Kaldor-Hicks (maximização da riqueza ao invés da maximização da utilidade) de eficiência para avaliar regulamentações expedidas pelo Estado. Ocorre que a formulação de Kaldor-Hicks particularmente deixa de fora da análise normativa a justiça distributiva (POSNER, 2001), entendida como a atribuição de bens (ou direitos) aos membros da comunidade, a fim de ser evitada a injustiça pela desigualdade, ou seja, o recebimento de um quantitativo menor de benefícios associado (ou não) a uma maior porção de encargos devidos a cada pessoa (BITTAR; ALMEIDA, 2002).

Em termos práticos, isso significaria que a mencionada regra sancionatória prevista no plano diretor não deveria considerar o comportamento dos agentes envolvidos numa transação imobiliária e inseri-lo num contexto em que tal prática é (ou não) abstratamente considerada como socialmente adequada, mas percebe-la enquanto comportamento concreto no qual determinado bem tem o mesmo valor (de mercado) para qualquer pessoa. Ou seja, quem compra (e vende) um imóvel, mesmo que em situação irregular no DF, ainda que fizesse a ponderação dos custos envolvidos, talvez não questionasse acerca da ilicitude do negócio que participa, mas se isso lhe acarretaria a satisfação de uma demanda (benefício) individual.

Talvez não seja essa a situação observada no quadrilátero federal pois, como indicado, a composição humana heterogênea do entorno bem como a formação do espaço urbano da capital não sugerem, ao menos enquanto totalidade, similitude do valor que se atribui nas negociações que envolvem o uso da terra, realizadas pelos habitantes do Distrito Federal. Nestas condições é que a análise econômica do direito tenta fornecer uma teoria explicativa do comportamento individual diante das regras (inclusive jurídicas) e as consequências destas na obtenção de eficiência dos resultados (ALVAREZ, 2006). Não se deve esquecer que no caso do Distrito Federal, como dito, há um histórico de regularização de situações em frontal desconformidade com o regramento em vigor.

Comisso se quer dizer que teria o legislador distrital a alternativa de impor a responsabilização 
por um eventual dano ao interesse público por danos causados mediante comportamentos razoáveis ex post, mas negligentes ex ante (PORAT, 2014). Mesmo que houvesse uma regularização posterior seria possível a imposição de um tipo de sanção não pela transação (contrato civil de compra e venda), mas pela relevância coletiva, no caso, do dano causado ${ }^{17}$.

Em certo sentido, a consequência acima indicada, relativa à elaboração da política pública fundiária, foi percebida já nos primeiros escritos da AED. Imagine-se uma situação na qual determinada atividade, a exemplo de uma fábrica, causando prejuízos à vizinhança que se encontra nas proximidades do complexo industrial, pela emissão de gases poluentes, afete um grande número de pessoas envolvidas numa ampla variedade de outras operações. Neste exemplo, os custos administrativos, como manter fiscalização diária, poderiam ser demasiadamente altos e, por outro lado, não seria adequado repassar aos agentes privados a tentativa de lidar e solucionar o problema.

Uma solução alternativa seria a regulamentação direta, ou seja, ao invés de um sistema normativo o qual pode ser modificado pelas transformações do mercado, o Estado poderia impor leis ambientais que determinassem o que o causador do prejuízo devesse ou não fazer e qual regra deveria ser obedecida. Porém, não há razão para supor que tais regras limitadoras de comportamentos, estabelecidas por uma administração falível e sujeita a pressões políticas, necessariamente aumentarão a eficiência com que o sistema econômico opera (COASE, 1960). Esta indicação se concentra na afirmação de que os custos de transação não são distintos de qualquer outro custo, significando que tanto para os atuais e futuros negociadores de imóveis no Distrito Federal, quanto para o poder público, há custos concretos envolvidos nas respectivas atividades, os quais deveriam ser considerados ao se elaborar o regramento aqui analisado.

Não se deve esquecer que quem busca utilizar o critério paretiano, supondo uma maneira de eliminar ou talvez apenas reduzir os custos de transação, deixa de considerar que não existe nenhuma diferença, na teoria ou na prática, entre a redução ou eliminação dos tais custos e qualquer outra inovação no conhecimento ou organização que poderia trazer melhoria na situação de todos os integrantes de uma comunidade (CALABRESI, 1961).

Hipoteticamente, a eficiência da política pública ocorreria, por um lado, se o bem-estar social fosse medido pelo ganho coletivo da medida e, por outro, se o termo (eficiência) for definido como a razão do máximo aumento possível do benefício do grupo, presumindo que todas as infrações às normas em jogo, que causem dano, fossem consideradas extintas por lei. Na prática, provavelmente, a eficiência seja diferente entre aqueles que infringem a lei mais por causa das diferenças nos custos de apreensão, ou seja, a avaliação individual do custo em deixar de seguir o comportamento desejado pela norma e convicção da punição do que a elasticidade da resposta dada pelo Estado diante da prática ilícita (BECKER, 1974). Um fator importante na determinação do mencionado custo, que pode apresentar grande variação, é o tempo decorrido entre prática do

17 Um argumento contrário ao exposto seria o de que se houvesse tal imposição, o Distrito Federal estaria invadindo a competência legislativa da União, prevista na Constituição Federal (art. 22, inc. I), e legislando sobre regras (civis) contratuais. Acredita-se que não seja o caso, pois o que aqui se defende diz respeito, por um lado, a típica normatização urbanística, de competência constitucional concorrente (art. 24, inc. I) e, por outro, não se dirige uma penalização pela feitura do contrato em si, mas as consequências que este pode gerar em face do interesse coletivo. 
delito e a aplicação da punição.

Sugere-se aqui que no regramento fundiário distrital, paralelamente ao estabelecer a sanção ex post no caso de transações irregulares de lotes, seja elaborada uma regra ex ante que forneça incentivos eficientes, tanto para os agentes integrantes da negociação, ou seja, os comportamentos atuais, quanto para eventuais danos provocados por futuras negligências. Isso porque enquanto uma regra ex ante poderia criar estímulos eficazes às práticas lícitas para o agente, levando-o a considerar todos os riscos envolvidos antes de tomar qualquer atitude, uma regra ex post que imponha somente penalidades induz uma desvantagem deficitária, porque permite a quem participa da transação ignorar alguns riscos, especialmente no caso do DF onde, como dito, há um histórico de regularização de situações ilícitas, no que se refere ao uso da terra.

Tal afirmação parte da premissa que o interesse social atua como modelo de mudança do status quo, a proteger o interesse particular e, na maioria dos casos, atuar conforme aquele primeiro determinará quantos perdem e quantos ganham, devendo estes serem mais numerosos (CACHO, 2012). Por intermédio da AED e da análise do custo-benefício das transações, são considerados outros elementos para a elaboração da política pública, os quais poderão interferir no comportamento futuro das pessoas que fazem contratos relativos a bens imóveis.

O derradeiro teste da análise do custo-benefício de uma política pública, empregando-se o conceito de eficiência de Kaldor-Hicks, é de natureza pragmática (POSNER, 2001), ou seja, se o seu uso melhora o desempenho governamental em qualquer sentido de melhoria que o observador considere apropriado.

É imperativo que a lei e as normas jurídicas - assim como sua aplicação pelo Poder Judiciário - criem incentivos que permitam à sociedade um maior bem-estar. Fundamental, nesse contexto, que a norma seja testada à luz de uma análise de custo-benefício social de modo a que apenas normas que aumentem o bem-estar social continuem a vigorar no ordenamento.

É imprescindível ao avaliar normas jurídicas que se atente a todos os agentes que são afetados pelas mesmas e não apenas a um determinado caso concreto em que se tem por exemplo apenas dois agentes. Um que perde e outro que ganha. As normas e sua aplicação tem efeitos sobre todos os agentes econômicos e sobre o nível de bem-estar da sociedade. Uma análise da norma deve levar isso em consideração e avaliar se a sociedade como um todo está em situação em que existe um benefício líquido com a mesma.

A norma jurídica cria incentivos e desincentivos aos distintos agentes da sociedade. Entender como esses incentivos e desincentivos ocorrem e operam é essencial para se pensar se os mesmos estão alinhados com os interesses da sociedade e como alterá-los caso não estejam. O aprofundamento deste tipo de discussão é imperativo em um ambiente em que as cidades crescem de forma desordenada, criando uma série de problemas ambientais, de segurança pública, de mobilidade urbana, dentre tantos outros.

Por tais razões é se que propõe, na elaboração da regra de comportamento, a consideração dos elementos indicados, visto que no caso da legislação fundiária do Distrito Federal, demonstrouse que o simples fato de haver normas sancionatórias, não impede a ocorrência de trocas ilícitas, o 
que pode revelar a inefetividade de valores implícitos (JARDIM; FRITZ, 2017) no PDOT ${ }^{18}$.

\section{CONCLUSÃO}

Como tópico final, são apresentadas algumas sugestões para o trabalho de elaboração de futuros regramentos fundiários no Distrito Federal. Em primeiro lugar, à própria definição do que se entenda por função social para a propriedade devem ser agregados outros paradigmas, a exemplo de uma função estrutural ${ }^{19}$. Caso contrário, a finalidade pública fundiária será objeto de debate entre defensores de uma matriz de orientação utilitarista e da valoração do útil social. Mas tal discussão não reverterá em ações eficientes.

Em segundo lugar, se utilizado o critério de Kaldor-Hicks na forma como originalmente proposto, enquanto componente para a tomada de decisão entre agentes, devem ser comparadas situações anteriores e posteriores de incremento da riqueza de maneira relevante, o suficiente para que possam compensar perdas (ou custos).

Por fim, valendo-se da avaliação de custo-benefício na política pública, como a que foi descrita, deveria aquela estar articulada com as possibilidades reais de barganha por parte dos agentes, os quais estabelecerem margens de negociação consideradas razoáveis aos olhos da lei, associada a um eficaz modelo fiscalizatório e de repressão às práticas ilícitas.

\section{REFERÊNCIAS}

ADLER, Matthew D; POSNER, Eric A. New foundations of cost-benefit analysis: a reply to Professor Sinden, Kysar, and Driesen. Regulation and Governance, New York, v. 3, p. 72-83, 2009.

ALVAREZ, Alejandro Bugallo. Análise econômica do direito: contribuições e desmistificações. Revista Estado, Direito e Sociedade, Rio de Janeiro, n. 29, p. 49-68, 2006. Disponível em: $<$ http://direitoestadosociedade.jur.puc-rio.br/media/Bugallo_n29.pdf $>$. Acesso em: 16 maio 2017.

BECKER, Gary S. Crime and punishment: an economic approach. In: BECKER, Gary S.; LANDES, William M. (Ed.). Essays in the economics of crime and punishment. New York: National Bureau of Economic Research/Columbia University Press, 1974. p. 1-54. Disponível em: <http://www.nber.org/chapters/c3624.pdf>. Acesso em: 26 abr. 2017.

BITTAR, Eduardo C. B.; ALMEIDA, Guilherme Assis de. Curso de filosofia do direito. 2. ed. São Paulo: Atlas, 2002.

CACHO, Angel Juarez. Los principios de interés social, orden público y apariencia de buen derecho. Coyoacán (Mexico): Raúl Juarez Carro Editorial, 2012.

18 Importantes desdobramentos desta forma de elaboração regra podem ser vistos, por exemplo, no debate relativo a formas de criar o engajamento da população para reduzir ou eliminar os vieses nas escolhas (SUNSTEIN; JOLLS, 2004) ou novas formas do Poder Judiciário decidir, valendo-se dos elementos da AED.

19 Entendida não como uma estrutura privada, mas da sociedade, necessária para reprodução do próprio sistema coletivo (PELLERINO, 2005). 
CALABRESI, Guido. Some thougts on risk distribuitions and the law of torst. Yale Law Journal, Yale, v. 70, n. 4, 1961. Disponível em: < http://digitalcommons.law.yale.edu/cgi/viewcontent. cgi? article $=3035 \&$ context $=$ fss_papers $>$. Acesso em: 26 abr. 2017.

COASE, Ronald. H. The problem of social cost. Journal of Law and Economics, New York, v. 3, 1960.

COOTER, Robert; ULEN, Thomas. Direito e economia. 5.ed. Porto Alegre: Bookman, 2010.

DAVID, René. Os grandes sistemas do Direito Contemporâneo: Direito Comparado. Tradução de Hermínio A. de Carvalho. Lisboa: Meridiano, 1978.

DAYRELL, Cristiano de Castro; TABAK, Benjamin Miranda. Uma análise econômica do Sistema Nacional de Informações Territoriais (SINTER): um problema de direito de propriedade. Revista de Direito da Cidade, Rio de Janeiro, v. 9, n. 4, p. 1529-1557, 2017.

GONZÁLEZ, Carlos Peña. El análisis económico de las instituciones legales. Apuntes de Derecho. Santiago (Chile), n. 9, p. 4-9, 2001.

GUIMARÃES, Ariane Costa. As alterações na legislação dos preços de transferência. Revista Dialética de Direito Tributário, São Paulo, n.212, p. 7-14, maio 2013.

JARDIM, Tiago Neu; FRITZ, Karen Beltrame Becker. Aplicação da lei na perspectiva da escolha pública: uma crítica utilitarista da construção política do direito. Economic Analysis of Law Review, Brasília, v. 8, n. 1, p. 81-96, 2017. Disponível em: <https://portalrevistas.ucb.br/index. php/EALR/article/view/7344>. Acesso em: 29 set. 2017.

LACERDA, Nadia Demoliner. Migração internacional a trabalho. São Paulo: LTr, 2014

PELLERINO, Giovani. Evolução do conceito de propriedade: da "função social” à "função estrutural". Revistas Veredas do Direito, Belo Horizonte, v. 2, n. 3, p. 33-46, 2005. Disponível em: <http://www.domhelder.edu.br/revista/index.php/veredas/article/view/115>. Acesso em: 17 abr. 2017.

PORAT, Ariel. Ex post right, ex ante wrong. Notre Dame Law Review, v. 89, n. 3, 2014.

Disponível em: <http://vlex.com/vid/post-right-wrong-507499594>. Acesso em: 16 maio 2017.

PORTO, Antônio José Maristrello; THEVENARD, Lucas. Pagamento Mínimo da Fatura do Cartão de Crédito: Informar ou Proibir? Conjuntura Econômica (Rio de Janeiro). v. 65, p. 60-65, 2011.

PORTO, Antônio José Maristrello; Galvão. Antônio F. Choice with Clouded Concepts. Economic Analysis of Law Review. v. 5, p. 46-68, 2014.

PORTO, Antônio José Maristrello; SANTOS, L. M. Cotas de reserva ambiental: uma interpretação da análise econômica do direito. Revista Estudos Institucionais. v. 3, p. 923-948, 2017.

PORTO, Antonio José Maristrello. Análise econômica do direito. 2013. Disponível em: <http:// direitorio.fgv.br/sites/direitorio.fgv.br/files/u100/analise_economica_do_direito_20132.pdf>. Acesso em: 16 abr. 2017. 
PORTO, Antonio José Maristrello; FRANCO, Paulo Fernando. Uma análise também econômica do direito de propriedade. Economic Analysis of Law Review, Brasília, v. 7, n. 1, p. 207-232, 2016. Disponível em: <https://portalrevistas.ucb.br/index.php/EALR/article/view/6473/pdf>. Acesso em: 29 set. 2017.

POSNER, Richard A. Values and consequences: an introduction to economic analysis of law. Law and Economic Review, Chicago, n. 53, 1998.

POSNER, Richard A. Cost-benefit analysis: definitions, justification, and comment on conference papers. In: ALDER, Matthew; POSNER, Eric (Ed.). Cost-benefit analysis: legal, economic and philosophical pespectives. Chicago: The University of Chicago Press, 2001. p. 317-341.

PRADO JUNIOR, C. A história econômica do Brasil. 16. ed. São Paulo: Brasiliense, 1998.

ROBINSON, Paul. H. Fair notice and fair adjudication: tow kinds of legality. 2005. Disponível em: <http://vlex.com/vid/fair-adjudication-kinds-legality-56729546>. Acesso em: 16 maio 2017.

RODRIGUES, Vasco. Análise econômica do direito: uma introdução. Coimbra: Edições Almedina, 2007.

SENNA, Homero; MONTEIRO, Clovis Z. Fundações no Direito na Administração, Instituto de Documentação. Rio de Janeiro: Fundação Getúlio Vargas, 1970.

SILVA, A. T. Relações Internacionais e meio ambiente: construindo uma agenda de governança policêntrica. In: Encontro ANNPAS, 3, Brasília, 2006.

STEINBERG, Marília; MANIÇOBA, Regina. Brasília Capital nacional-regional: Brasília cidade mundial? In: V Seminario Internacional de la RII. Toluca, Méx., 21-24 septiembre 1999.

SUNSTEIN, Cass R.; JOLLS, Cristine. Debiasing through law. 2004. Disponível em: $<$ http://chicagounbound.uchicago.edu/cgi/viewcontent.cgi?article=1157\&context=law_and_ economics>. Acesso em: 29 set. 2017.

SUNSTEIN, Cass R. One Case at a Time: Judicial Minimalism on the Supreme Court. Cambridge: Harvard University Press, 1999.

SZTAJN, Rachel. Direito e economia. Revista de Direito Mercantil, São Paulo, n. 137, p. 228232, 2005.

TABAK, Benjamin Miranda. A Análise econômica do direito: proposições legislativas e políticas públicas. Revista de Informação Legislativa, Brasília, v. 52, n. 205, p. 321-345, jan./mar. 2015

TABAK, Benjamin Miranda; FERREIRA FILHO, Paulo Sérgio. Um limite temporal para a regularização fundiária urbana em áreas de preservação permanente: as análises econômica e comportamental do direito e proteção ao meio ambiente. Veredas do Direito, Belo Horizonte, v. 13, n. 27, 2016.

TYBUSCH, Jerônimo Siqueira; GREGORI, Isabel Christine Silva de. Gestão democrática, participação local e esfera pública na efetivação do estatuto das cidades como garantidor do meio ambiente cultural. Direitos Culturais, Santo Ângelo/RS, n. 11, p. 85-108, 2011. 
VALDÉS PRIETO, Domingo. Libre competencia y monopolio. Santigo (Chile): Jurídica de Chile, 2006, p. 158-170.

Como citar: OLIVEIRA, Marco Tulio Chaves; TABAK, Benjamin Miranda. A contribuição da análise de custo-benefício na avaliação da eficiência de regras fundiárias do distrito federal. Revista do Direito Público, Londrina, v. 13, n. 3, p. 72-90, dez. 2018. DOI: 10.5433/24157108104-1.2018v13n3 p 72. ISSN: 1980-511X.

Recebido em: 22/06/2017

Aprovado em: 07/11/2018

1 Dados acessíveis ao público e obtidos no site oficial do TJDFT, disponível em http://tjsw612. tjdft.jus.br/QvAJAXZfc/opendoc.htm?document=Documentos\%2FCORREGEDORIA\%20-\%20 Mapa\%20Estat\%C3\%ADstico.qvw\&host=QVS\%40tjsw612\&anonymous=true, acessado em 01/05/2017, às 18:30. Tal quantitativo refere-se a protocolizações de ações de reintegração e/ou manutenção de posse feitas na Primeira Vara da Fazenda Pública do Distrito Federal no período considerado. Deve-se registrar, porém, que a partir do ano de 2010 houve redução numérica de tais processos. 